\title{
Histological investigations of muscle atrophy and end plates in two critically ill patients with generalized weakness
}

\author{
J. H. J. Wokke ${ }^{1,2}$, F. G.I. Jennekens ${ }^{1,2}$, C. J.M. van den Oord $^{1,2}$, \\ H. Veldman ${ }^{1}$ and J. van Gijn ${ }^{2}$ \\ ${ }^{1}$ Laboratory of Neuromuscular Diseases, and ${ }^{2}$ University Department of Neurology. University of Utrecht, \\ Utrecht (The Netherlands)
}

(Received 30 May, 1988)

(Revised, received 5 July, 1988)

(Accepted 5 July, 1988)

\section{SUMMARY}

We describe pathological alterations at the light microscopical and ultrastructural level of motor end plates and muscle fibres in 2 critically ill patients with generalized muscular atrophy and weakness. Axonal degeneration of intramuscular nerve fibres was not conspicuous. The sural nerve in one patient showed only minor abnormalities. There was a marked atrophy of type 1 and especially type 2 muscle fibres. Nodal and ultraterminal nerve sprouts were seen in both biopsies. Motor end plates showed features of regeneration. They were enlarged in one patient. This patient was treated for a prolonged period with vecuronium bromide. Pharmacological denervation may explain the presence of fibrillation potentials, and, partially, of the histological abnormalities. Another factor which must be considered is inhibition of neuromuscular transmission by antibiotics. In addition to disuse atrophy and a minor degree of axonal neuropathy, the production of muscle proteolytic factors may be involved in the rapidly occurring massive loss of muscle fibre size in critically ill patients.

Key words: Critical illness; Muscle atrophy; Motor end plate; Sprouting; Vecuronium bromide; Aminoglycosides

Correspondence to: Dr. J.H.J. Wokke, Laboratory of Neuromuscular Diseases, University Hospital Utrecht, Catharijnesingel 101, 3511 GV Utrecht, The Netherlands. 


\section{INTRODUCTION}

Muscle atrophy and weakness leading to difficulty in weaning from the ventilator, develop frequently in patients with critical illness (sepsis and multiple organ dysfunction), complicating a variety of primary diseases (Roelofs et al. 1983; Bolton et al. 1984; Op de Coul et al. 1985; Zochodne et al. 1985, 1987; Williams et al. 1986; Bolton 1987; Lycklama à Nyeholt and Troost 1987). Electrophysiological studies have shown spontaneous muscle activity and reduced amplitudes of compound muscle action potentials, and also of sensory nerve action potentials. Conduction velocities of motor and sensory nerves, distal latencies and F-wave latencies are usually normal (Op de Coul et al. 1985; Bolton et al. 1986; Bolton 1987; Lycklama à Nyeholt and Troost 1987; Zochodne et al. 1987). Pathological examination may show a mild to moderate degree of axonal degeneration of peripheral nerves, and atrophy and necrosis of muscle fibres (Bolton et al. 1984; Zochodne et al. 1985, 1987). Polyneuropathy from an unknown toxic or metabolic cause has been suggested to underly these abnormalities.

We report the results of a light and electron microscopical study of intramuscular nerves, motor end plates and muscle in 2 critically ill patients with generalized weakness and atrophy. Axonal degeneration was not prominent. We suggest that polyneuropathy in itself was not sufficient to cause the rapid decrease of muscle fibre size in these patients. Other factors which must be considered are disuse due to neuromuscular blockade, and the production of muscle proteolytic factors and of cachectin in critically ill patients.

\section{PATIENTS AND METHODS}

\section{Patients}

Case 1. A 47-year-old woman fell from a staircase and was admitted because of a posterior fossa subdural hematoma. She aspirated when cardiac arrest and apnea occurred, and was resuscitated. After surgery, pneumonia and sepsis developed. Artificial ventilation was necessary for the adult respiratory distress syndrome. Complete muscle relaxation was obtained with vecuronium bromide in the first week, and from the 5 th through the 8 th week. During several periods of fever she was treated with gentamicin and clindamycin. In the 10 th week she could not be weaned from the ventilator. Neurological examination showed complete paralysis and areflexia. Only the pupillary reflexes were preserved. Generalized muscle atrophy was noted. Laboratory analysis after the first week revealed anemia, leukocytosis, thrombopenia and hypalbuminemia. Serum CK activity was $206 \mathrm{U} / 1$ (normal <105) in the 3rd week. Electromyography showed fibrillation potentials and positive sharp waves in proximal and distal muscles of arms and legs in the 10th week. There was no decrement of the action potential of the abductor pollicis brevis muscle following $3 \mathrm{~Hz}$ stimulation of the median nerve. The amplitude of the compound muscle action potential of this muscle was $425 \mu \mathrm{V}$ (normal $>5 \mathrm{mV}$ ). Nerve conduction velocity studies showed normal values in the right median, deep peroneal and sural nerves. The amplitude of the action potential of the sural nerve was normal with $14.8 \mu \mathrm{V}$. Sural nerve and external intercostal muscle biopsies were taken. She died from multi-organ dysfunction in the 15 th week of admission.

Case 2. A 55-year-old man had idiopathic cardiomyopathy for 7 years. Congestive heart failure caused respiratory distress, and artificial ventilation was required. During the first week vecuronium bromide was given for complete muscle relaxation and later on midazolam. Infection was treated with tobramycin. After 7 weeks he still could perform motor tasks. During a new period of deterioration with fever he was treated with vancomycin. Progressive renal failure necessitated peritoneal dialysis. In the 10th week generalized muscle atrophy was noted, and he could not be weaned from the ventilator. Neck flexor 
and extensor muscles were weak. Arm muscles were severely weak, the legs were paralytic. Sensation seemed unimpaired. Myotatic reflexes were low in the arms and absent in the legs. Anemia and hypalbuminemia were present. Renal function deteriorated. Thrombopenia was present on admission and in the 9th week. Electromyography demonstrated polyphasic motor unit potentials and a reduced pattern in the left deltoid and biceps brachii muscles. Motor and sensory nerve conduction velocities and amplitudes were normal in the left median, tibial and sural nerves. An external intercostal muscle biopsy was taken. Motor function gradually recovered, but the patient died from deterioration of cardiac function in the 14th week.

\section{Methods}

The sural nerve biopsy from case 1 was divided into 3 parts. One part was rapidly frozen in isopentane cooled in liquid nitrogen. Cryostat sections were stained according to routine histological and histochemical methods. A second part was fixed in a glutaraldehyde solution, postfixed in a $1 \%$ osmium tetroxide solution and embedded in Epon 812. Semithin transverse sections were stained with paraphenylene diamine for quantitative studies of myelinated nerve fibres. Ultrathin sections of selected areas were contrasted with uranyl acetate and lead citrate and used for electron microscopy. A third part of the nerve was used for teased fibre preparations.

Parts of the intercostal muscle biopsies from both patients were rapidly frozen. Sections were stained according to routine histological and histochemical procedures, and according to the Pestronk and Drachman (1978) method for intramuscular nerves and end plates. A second part of the muscle was fixed in a stretched position in a periodate lysine paraformaldehyde solution. Half of this part was postfixed in a $1 \%$ osmium tetroxide solution, dehydrated and embedded in Epon 812. Motor end plates were identified in $1-\mu \mathrm{m}$ sections stained with toluidine blue. Ultrathin sections from regions with end plates were contrasted with uranyl acetate followed by lead citrate and viewed in a Zeiss 109 electron microscope. The other half was used for localization of acetylcholine receptors (AChRs) at the ultrastructural level with a method using a monoclonal antibody (Smit et al. 1987).

\section{Quantitative analysis}

At the light microscopical level we measured the diameters of at least 100 type 1 and 100 type 2 muscle fibres on cross sections. Camera lucida drawings at $1000 \times$ magnification were made of end plates in sections stained with the silver cholinesterase (ChE) method. Only end plates on longitudinally sectioned muscle fibres with an innervating axon of at least $50 \mu \mathrm{m}$ length were analyzed. We calculated the terminal innervation ratio (TIR $={ }^{\mathrm{n}}$ muscle fibres $/{ }^{\mathrm{n}}$ axons (Coërs et al. 1973)). The largest diameters of approximately $30 \mathrm{ChE}$ areas were measured. We also measured diameters of end plates after marking with a monoclonal antibody for localization of AChR.

At the ultrastructural level quantitative analysis of neuromuscular junctions (NMJs) was performed as previously described (Fig. 1; Oosterhuis et al. 1987).

\section{Statistical analysis}

Results from a study of age-related changes of the morphology of end plates were used as a control. The mean values of both patients were compared with values from controls by means of Wilcoxon's two samples test. 


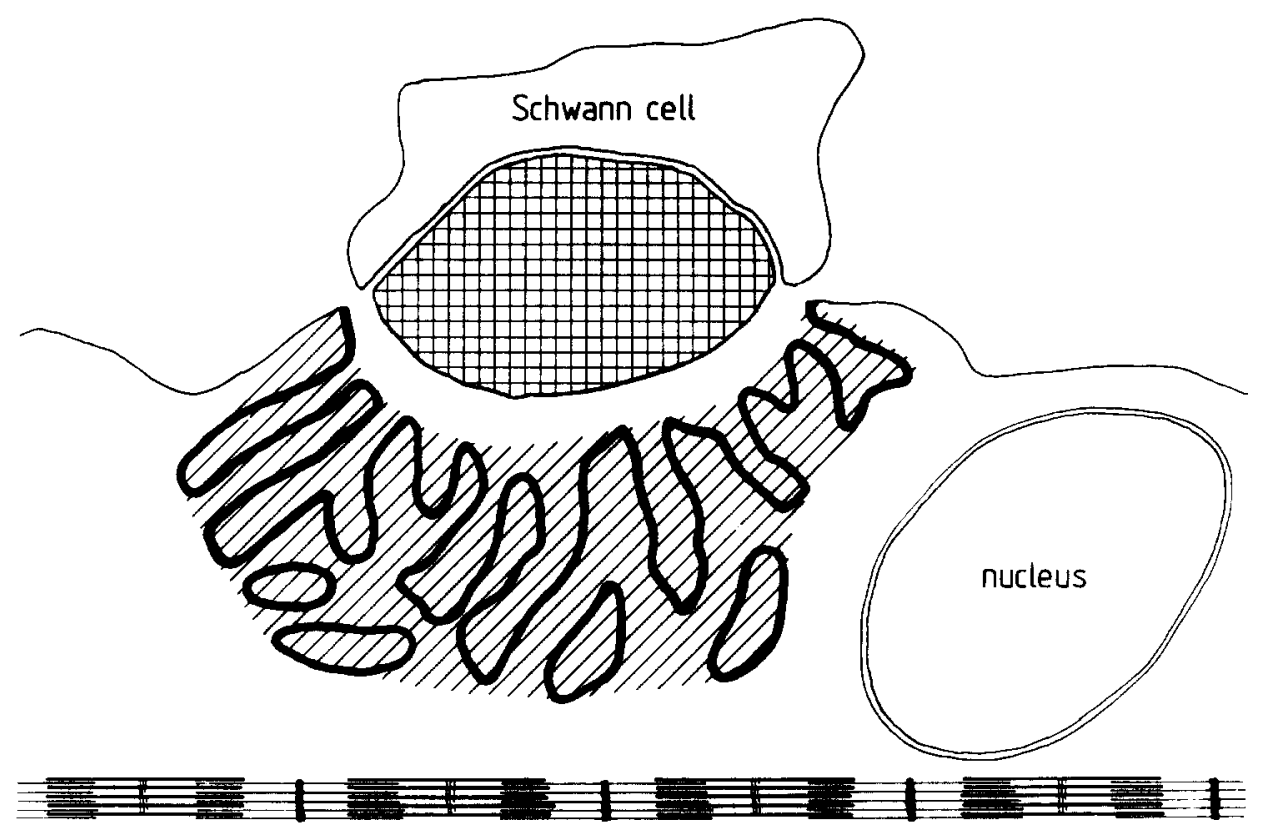

nerve terminal area

$1 / 1 /$, postsynaptic area of clefts and folds

postsynaptic membrane length

Fig. 1. Schematic drawing of analyzed parameters of the ultrastructure of the neuromuscular junction (NMJ).

\section{RESULTS}

Sural nerve

The sural nerve of case 1 showed only minor abnormalities. Few myelinated fibres showed evidence of axonal degeneration. Electron microscopy revealed the occasional presence of membrane lipids in axons of myelinated fibres. No abnormalities were seen in unmyelinated fibres. Quantitative analysis showed a density of myelinated fibres of $5355 / \mathrm{mm}^{2}$, which is at the borderline of normality (Jacobs and Love 1985; Ouvrier et al. 1987). The total number of myelinated fibres in the sural nerve was 4337 which is also just subnormal (Jacobs and Love 1985). The histogram of nerve fibre diameters showed a normal bimodal distribution with peaks at 3 and $8-9 \mu \mathrm{m}$.

\section{External intercostal muscle}

\section{Qualitative observations}

The muscle biopsies from both patients showed severe abnormalities, which were most pronounced in case 1 . There was a striking degree of muscle fibre atrophy. 


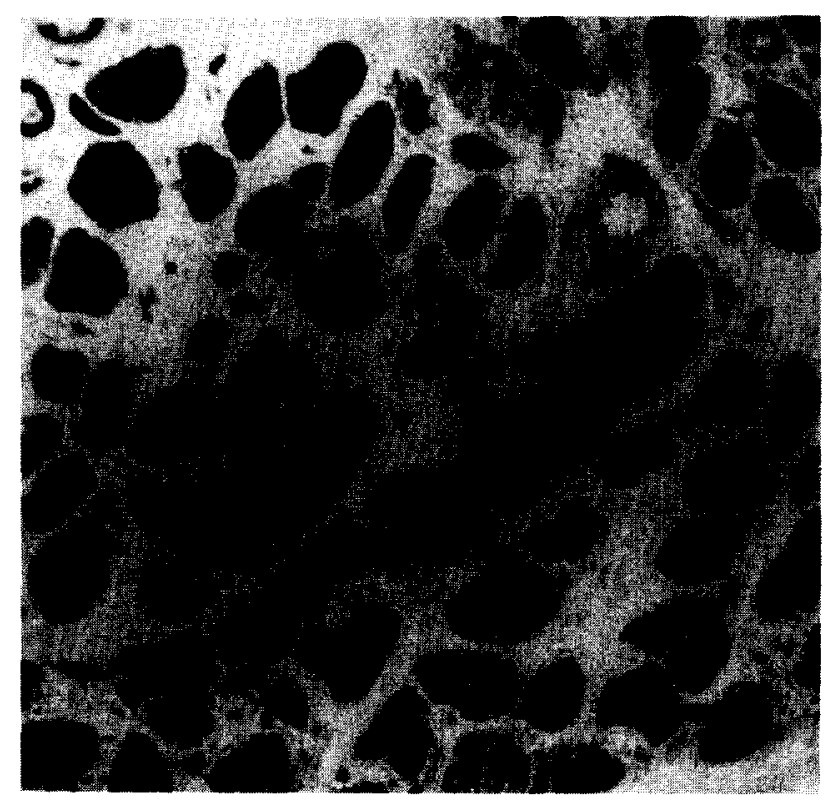

Fig. 2. Cross section of the external intercostal muscle biopsy from case 1 (myosin ATPase, pH 9.4). All type 2 muscle fibres are atrophic (dark). Atrophy of type 1 fibres is present, though less prominent (bar $=50 \mu \mathrm{m}$ ).

Occasional fibres were necrotic. Phagocytosis and inflammatory cell reactions were not seen. In transverse sections, atrophic fibres were somewhat angulated and often irregularly shaped. Myosin ATPase activity showed a mosaic pattern of type I and II fibres with predominance of type I fibres, as is customary for this muscle (unpublished observations) (Fig. 2). Type II fibres were more atrophic than type I fibres. Type grouping was absent. Ultrastructural examination demonstrated a variable but often severe loss and disarray of myofibrils in the muscle fibres (Fig. 3). In many muscle fibres streaming of $Z$ disks was seen.

Evidence of axonal degeneration of nerve fibres in intramuscular nerves was infrequently found. Some fibres showed myelin clefts or myelin disarray. We were not always sure whether this was due to fixation artefacts or to degeneration. Intramuscular nerve fibres showed many nodal, preterminal and ultraterminal sprouts in both biopsies (Fig. 4B,C). Some of these sprouts had large terminal axon swellings (Fig. 4D).

At the ultrastructural level, pathological changes of preterminal myelinated axons and terminal axons were not seen. Terminal axons could be seen lying alongside of muscle fibres, making contact with them by means of many small NMJs, especially in case 1 (Fig. 5A). The postsynaptic areas were often little differentiated. Junctional folds were short and unbranched and secondary clefts were consequently shallow as in immature NMJs. Postsynaptic densities were present on these short junctional folds. End plates with simple NMJs were also present in case 2, though not extending over a large distance as in case 1 . NMJs with large, well developed postsynaptic areas were also seen in case 2 . In both patients the junctional sarcoplasm contained many coated 


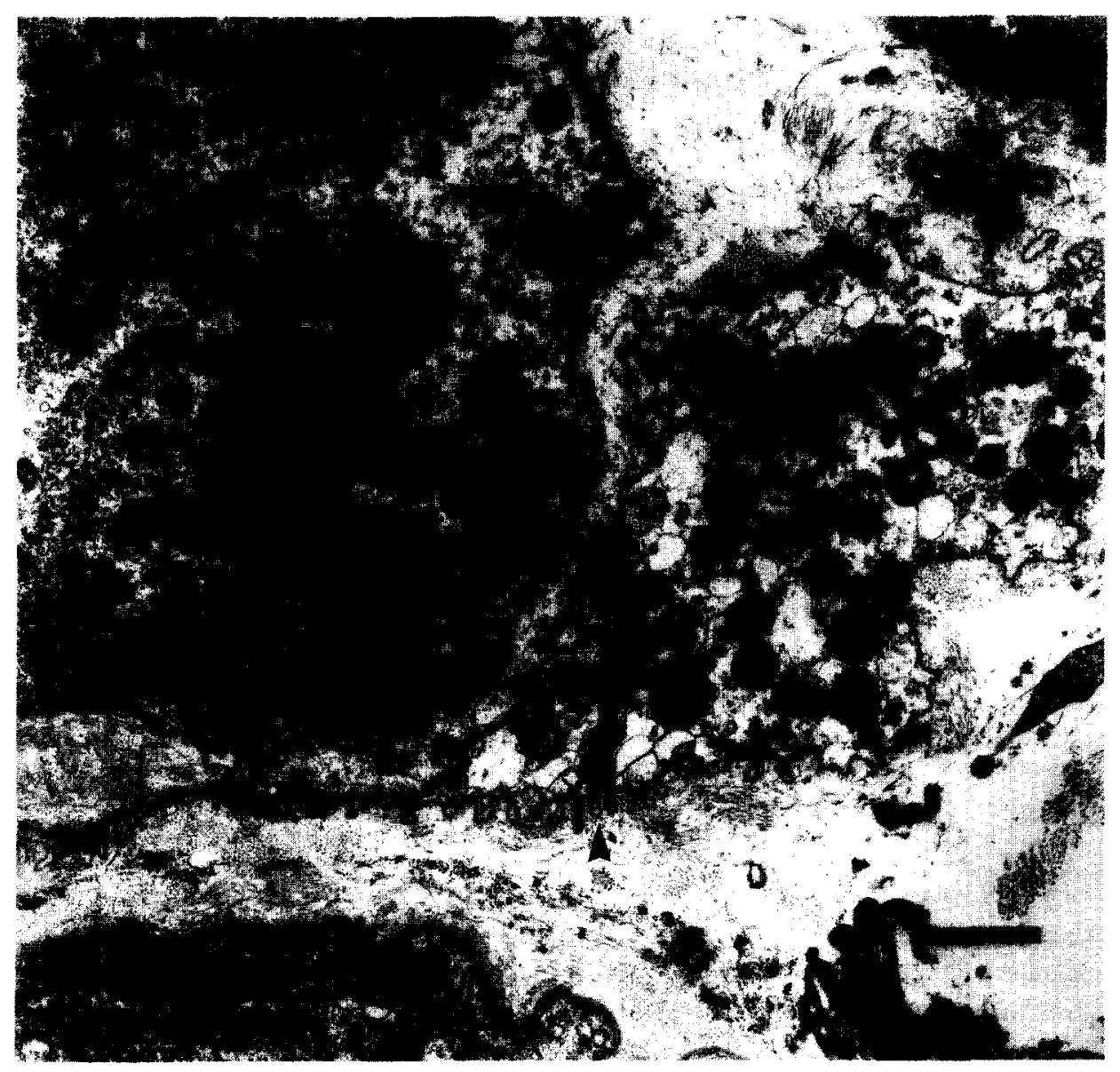

Fig. 3. Electron micrograph of cross section of muscle. In the muscle fibre at the left some myofibrils are present (asterisk). In a second atrophic muscle fibre at the right no myofibrils can be seen. Many small basal lamina folds can be seen (arrowheads) (bar $=2 \mu \mathrm{m}$ ).

vesicles and coated pits (Fig. 6). AChRs were demonstrated at the postsynaptic membrane, including the short junctional folds (Fig. 5B). In the few deep folds the reaction product was present only on the upper parts of the folds. Beneath some end plates normal sarcomeres were recognized, whereas under others only unorganized myofibrils could be seen (Fig. 5A), or myofibrils were totally absent in the plane of section.

\section{Quantitative analysis}

The mean diameter of type I fibres was $17.1 \mu \mathrm{m}$ in case 1 and $32.0 \mu \mathrm{m}$ in case 2 , and of that of type II fibres $12.6 \mu \mathrm{m}$ and $16.2 \mu \mathrm{m}$. In 9 adult controls the mean diameters of type I fibres varied between 39.4 and $66.1 \mu \mathrm{m}$, and those of type II fibres between 38.4 and $63.6 \mu \mathrm{m}(P<0.05)$. 


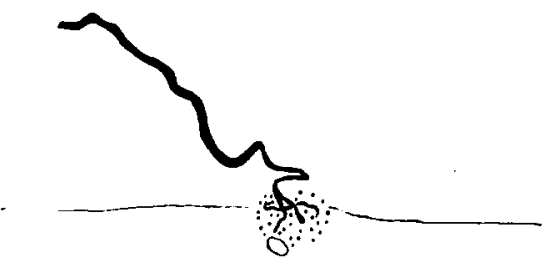

A

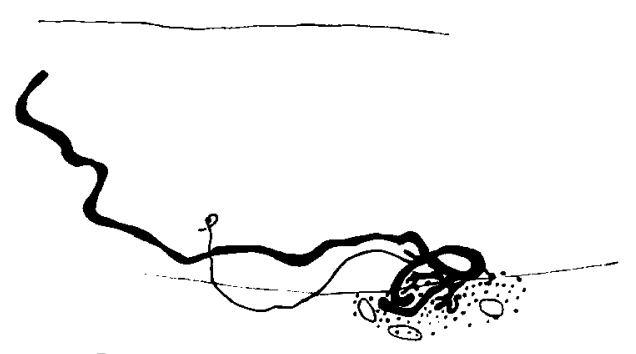

B

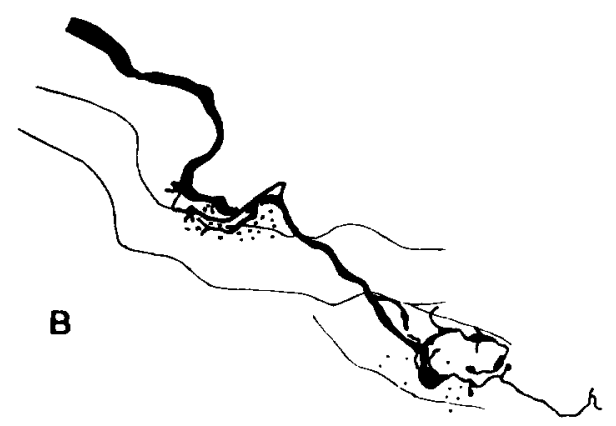

C

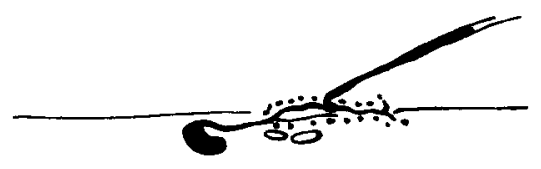

D

Fig. 4. Camera lucida drawings of light microscopy after silver cholinesterase (ChE) staining of end plates. $\mathrm{ChE}$ area is dotted, oval structure represents nucleus. (A) control biopsy. (B) case 1: motor axon innervates 2 muscle fibres. Ultraterminal sprouts originate in the end plate on the lower fibre. (C) case 1: large ultraterminal sprout can be seen at the left. (D) case 2: ultraterminal sprout with terminal axon swelling leaves the motor end plate $(\mathrm{bar}=50 \mu \mathrm{m})$.

TIR as calculated from 50 axons was 1.26 in case 1 and 1.40 in case 2. In 12 adult controls TIR fluctuated between 1.06 and 1.30 (not significant).

Most muscle fibres had 1 distinct ChE positive area. However, the staining was usually weak in the patients compared with controls. The largest diameter of the ChE area was $28.3 \pm 1.4 \mu \mathrm{m}$ in case 1 (mean \pm SEM) and $24.3 \pm 1.4$ in case 2 . In 15 controls this diameter varied between $18.8 \pm 1.4 \mu \mathrm{m}$ and $26.5 \pm 1.7 \mu \mathrm{m}$ (n.s.).

After marking of end plates with the monoclonal antibody method for localization of AChRs, end plate diameters of $27.6 \pm 1.6 \mu \mathrm{m}$ and of $15.9 \pm 0.7 \mu \mathrm{m}$ were measured in cases 1 and 2 respectively. In 8 controls this value varied between $14.5 \pm 0.7 \mu \mathrm{m}$ and $21.0 \pm 0.8 \mu \mathrm{m}$ (n.s.).

Quantitative analysis of the ultrastructure of NMJs confirmed the postsynaptic simplicity in case 1 (Table 1). Values in case 2, though low, did not differ from controls. Only the nerve terminal area was significantly larger in both patients compared with controls $(P<0.05)$.

\section{DISCUSSION}

The most prominent histological abnormalities in these critically ill patients were sprouting of intramuscular nerves and atrophy of type I and, especially type II muscle 


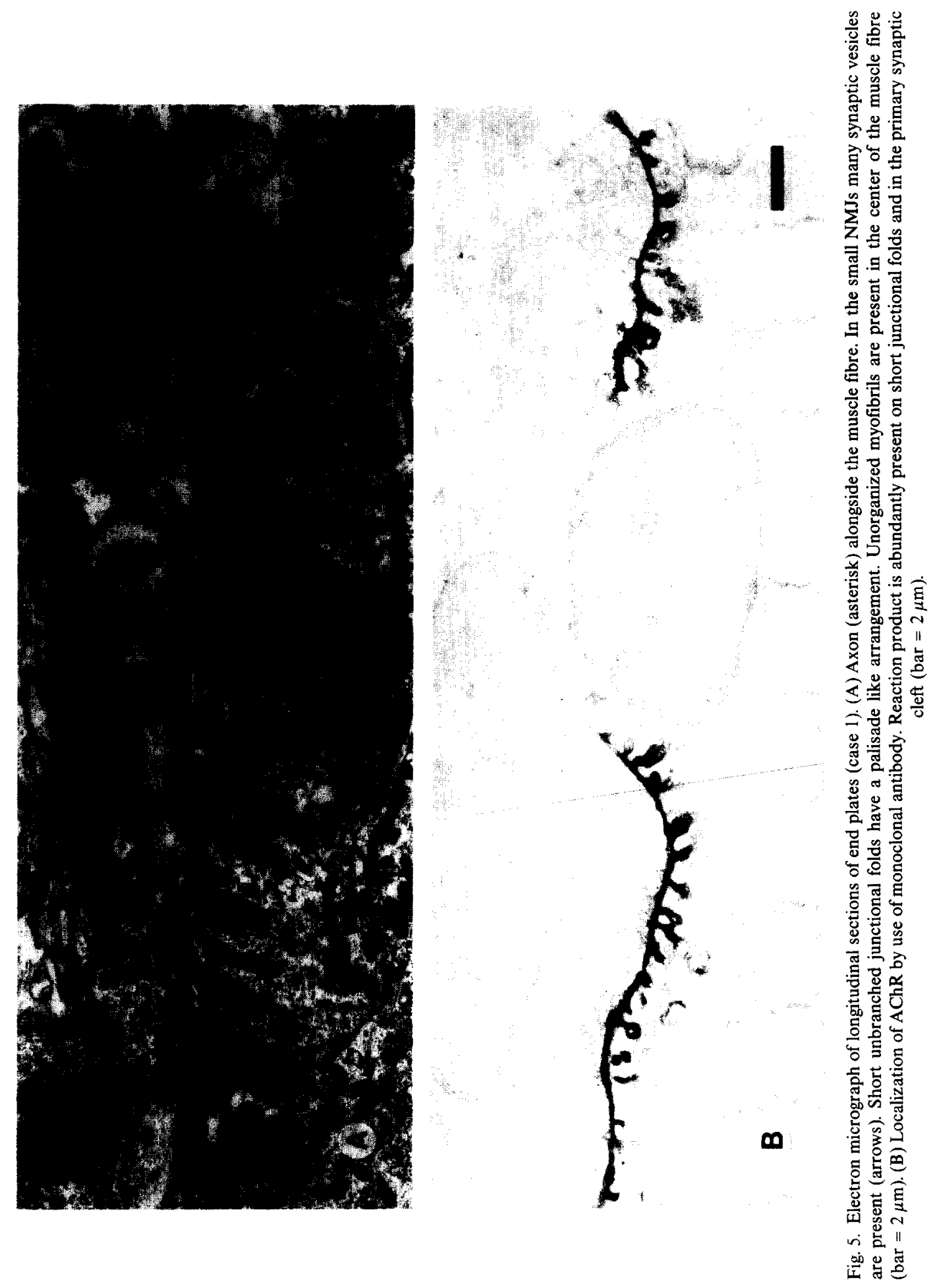




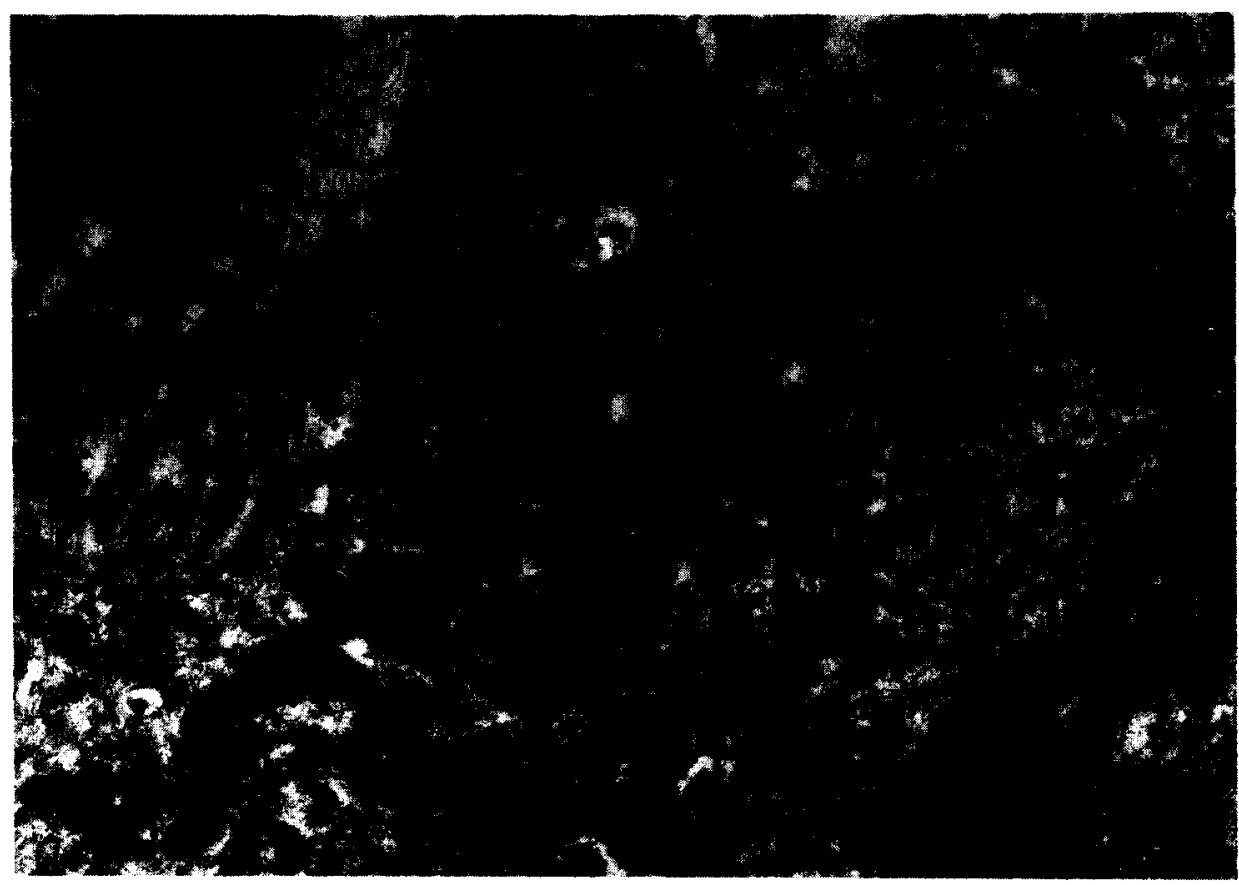

Fig. 6. Electron micrograph of detail of NMJ from case 2. A coated vesicle (open arrow head) is present in the junctional sarcoplasm at a secondary synaptic cleft. Coated pits (closed arrow heads) communicate with secondary clefts (bar $=1 \mu \mathrm{m})$.

TABLE 1

MORPHOMETRICAL ANALYSIS OF NMJS IN 2 CRITICALLY ILL PATIENTS

Mean values $\pm \mathrm{SE}$ are given.

\begin{tabular}{|c|c|c|c|c|c|}
\hline & Age & $\begin{array}{l}\text { No. of } \\
\text { NMJs }\end{array}$ & $\begin{array}{l}\text { Nerve terminal } \\
\text { area }\left(\mu \mathrm{m}^{2}\right)\end{array}$ & $\begin{array}{l}\text { Postsynaptic membrane } \\
\text { length }(\mu \mathrm{m})\end{array}$ & $\begin{array}{l}\text { Postsynaptic area } \\
\text { of clefts and } \\
\text { folds }\left(\mu \mathrm{m}^{2}\right)\end{array}$ \\
\hline $\begin{array}{l}\text { Case } 1 \\
\text { Case } 2 \\
9 \text { adult } \\
\text { controls }^{a}\end{array}$ & $\begin{array}{l}47 \\
55 \\
24-77\end{array}$ & $\begin{array}{r}11 \\
26 \\
178\end{array}$ & $\begin{array}{l}4.4 \pm 0.8 \\
5.8 \pm 1.6 \\
2.3 \pm 0.5 \\
\text { to } \\
4.2 \pm 0.6\end{array}$ & $\begin{array}{l}26.3 \pm 1.2 \\
49.6 \pm 5.5 \\
39.8 \pm 5.8 \\
\text { to } \\
99.1 \pm 10.7\end{array}$ & $\begin{array}{l}5.8 \pm 0.6 \\
9.7 \pm 1.1 \\
7.3 \pm 1.0 \\
\text { to } \\
15.0 \pm 1.7\end{array}$ \\
\hline
\end{tabular}

a For all measures the range between the lowest and the highest mean values is given.

fibres. We could not determine whether all these atrophied fibres were innervated. However, with the light microscope we could demonstrate that many small sized muscle fibres received an innervating axon. At the ultrastructural level muscle fibres with complete disarray of recognizable myofibrillar organization and well-preserved end plates were seen. Actually many NMJs showed features of regeneration, i.e. immature, simple junctional folds (Desaki and Uehara 1987), and coated vesicles and coated pits 
open to junctional folds, indicating $\mathrm{AChR}$ transport to the postsynaptic membrane (Bursztajn and Fischbach 1984; Desaki and Uehara 1987). In addition, in the first patient enlargement of end plates due to de-novo formation of NMJs was noted. Although some degree of axonal degeneration could not be excluded in the sural nerve biopsy from the first patient, axonal degeneration was not prominent in intramuscular nerves in the severely affected intercostal muscle from both patients. After experimental denervation atrophy of muscle fibres usually takes a rather slow course (for review, see Jennekens 1982). Consequently, other factors than polyneuropathy alone must be considered in an attempt to explain the rapidly occurring, enormous decrease of muscle fibre size in both critically ill patients.

The histological abnormalities in the first patient differed from those in the second patient on two points. Firstly, enlargement of end plates and de-novo formation of NMJs was seen. Secondly, the atrophy of muscle fibres was more expressed. In the course of her disease this patient was treated for a total of 28 days with vecuronium bromide. She also received the aminoglycoside gentamicin, and clindamycin. These three drugs affect neuromuscular transmission. Vecuronium bromide, a pancuronium analogue (Bowman 1983; Marshall et al. 1980), causes like (+)-tubocurarine a powerful mainly postsynaptic blockade of neuromuscular transmission, by a non-depolarizing competitive antagonism with acetylcholine for the AChR (Standaert 1984). The neuromuscular blocking properties of the aminoglycosides and of clindamycin are less powerful (Argov and Mastaglia 1979; Torda 1980; Sokoll and Gergis 1981). They result mainly from a presynaptic effect on acetylcholine release (Sokoll and Gergis 1981). Gentamicin reduces the quantal content of the end plate potential (Torda 1980). Clindamycin increases the frequency of miniature end plate potentials but decreases their amplitude (Sokoll and Gergis 1981). It also affects receptor sensitivity and has a direct depressant effect on the muscle membrane. Both drugs potentiate the effects of (+)-tubocurarine (Snavely and Hodges 1984). Following prolonged, experimental, pharmacological blockade of neuromuscular transmission with curare (Berg and Hall 1975; Wernig et al. 1980) and other agents (Grinnell 1986) a decrease of the resting membrane potential (RMP) of the muscle fibre precedes the occurrence of fibrillations, and of decreased synthesis and increased degradation of muscle proteins leading to atrophy. Sprouting of intramuscular nerve fibres and enlargement of end plates are histological features of this blockade (Wernig et al. 1980; Grinnell 1986). Treatment muscle relaxants during artificial respiration is often applied in critically ill patients (Op de Coul et al. 1985; Kupfer et al. 1987). Op de Coul et al. (1985) suggested that muscle weakness and fibrillation potentials might be the consequence of prolonged neuromuscular transmission block in some patients.

The production of muscle proteolytic factors, which has been demonstated in patients with fever, sepsis and trauma (Baracos et al. 1983; Clowes et al. 1983) may serve as an alternative explanation for weakness and atrophy in critically ill patients. The purified human leukocytic pyrogen, interleukin-1, stimulates protein degradation in rat muscles (Baracos et al. 1983). The polypeptide cachectin, which is produced by macrophages in response to endotoxin, binds to adipocytes and myoblasts, and stimulates interleukin-1 production (Beutler et al. 1985; Beutler and Cerami 1987). 
Cachectin causes a decrease of the RMP of rat skeletal muscle fibres (Tracey et al. 1986). A decrease of the RMP was also demonstrated in critically ill patients (Cunningham et al. 1971).

We conclude from the above, that muscle atrophy and weakness in critically ill patients are multiconditional: in addition to axonal neuropathy, disuse and breakdown of muscle proteins by proteolytic factors are likely to be involved in individually variable degrees. The prognosis of muscle weakness and atrophy in critically ill patients is often rather favourable. Patients who recover from their primary disease may regain most of their previous strength after a period of weeks to months (Bolton et al. 1984; Op de Coul et al. 1985; Williams et al. 1986).

\section{ACKNOWLEDGEMENTS}

L. E. C. Verhoeven, MD, referred the first patient. H. Franssen, MD, performed the electrophysiological studies. Mrs. E. Budelman-Verschuren and Mrs. M. Schipper prepared the manuscript. This study was supported by a grant from the Prinses Beatrix Fonds (to F. G.I.J.).

\section{REFERENCES}

Argov, Z. and F. L. Mastaglia (1979) Disorders of neuromuscular transmission caused by drugs. $N$. Engl. J. Med., 301: 409-413.

Baracos, V., H.P. Rodeman, C.A. Dinarello and A.L. Goldberg (1983) Stimulation of muscle protein degradation and prostaglandin $\mathrm{E}_{2}$ release by leukocytic pyrogen (interleukin-1). N. Engl. J. Med., 308: $553-558$.

Berg, D.K. and Z.W. Hall (1975) Increased extrajunctional acetylcholine sensitivity produced by chronic post-synaptic neuromuscular blockade. J. Physiol., 244: 659-676.

Beutler, B. and A. Cerami (1987) Cachectin: more than a tumor necrosis factor. N. Engl. J. Med., 316 : 379-385.

Beutler, B., J. Mahoney, N. Le Trang, P. Pekala and A. Cerami (1985) Purification of cachectin, a lipoprotein lipase suppressing hormone secreted by endotoxin-induced RAW 264.7 cells. J. Exp. Med., 161: 984-995.

Bolton, C.F. (1987) Electrophysiologic studies of critically ill patients. Muscle Nerve, 10: 129-135.

Bolton, C.F., J.J. Gilbert, A.F. Hahn and W.J. Sibbald (1984) Polyneuropathy in critically ill patients. J. Neurol. Neurosurg. Psychiat., 47: 1223-1231.

Bolton, C.F., D.A. Laverty, J.D. Brown, N.J. Witt, A.F. Hahn and W.J. Gibbald (1986) Critically ill polyneuropathy: electrophysiological studies and differentiation from Guillain-Barré syndrome. $J$. Neurol. Neurosurg. Psychiat., 49: 563-573.

Bowman, W.C. (1983) Preclinical pharmacology of vecuronium bromide. In: S. Agoston (Ed.), Clinical Experiences with Norcuron ${ }^{\infty}$, Excerpta Medica Current Clinical Practice Series, No. 6, Amsterdam, pp. $7-19$.

Bursztajn, S. and G. D. Fischbach (1984) Evidence that coated vesicles transport acetylcholine receptors to the surface membrane of chick myotubes. J. Cell. Biol., 98: 498-506.

Clowes, Jr, G.H.A., B.C. George, C. A. Villee and C. A. Saravis (1983) Muscle proteolysis induced by a circulating peptide in patients with sepsis or trauma. N. Engl. J. Med., 308: 545-552.

Coërs, C., N. Telerman-Toppet and J.M. Gérard (1973) Terminal innervation ratio in neuromuscular diseases I. Methods and controls. Arch. Neurol., 29: 210-214.

Cunningham, Jr., J. N., N. W. Carter, F. C. Rector and D.W. Seldin (1971) Resting transmembrane potential in normal subjects and severely ill patients. J. Clin. Invest., 50: 49-59. 
Desaki, J. and Y. Uehara (1987) Formation and maturation of subneural apparatures at neuromuscular junctions in postnatal rats: a scanning and transmission electron microscopical study. Dev. Biol., 119 : 390-401.

Grinnel, A.D. (1986) Trophic interactions between nerve and muscle. In: A.G. Engel and B.Q. Banker (Eds.), Myology, McGraw Hill, New York, pp. 359-39l.

Jacobs, J.M. and S. Love (1985) Qualitative and quantitative morphology of human sural nerve at different ages. Brain, 108: 897-924.

Jennekens, F. G. I. (1982) Neurogenic disorders of muscle. In: F. L. Mastaglia and J. Walton (Eds.), Skeletal Muscle Pathology, Churchill Livingstone, Edinburgh, pp. 204-234.

Kupfer, Y., D.G. Okrent, R.A. Twersky and S. Tessler (1987) Disuse atrophy in a ventilated patient with status asthmaticus receiving neuromuscular blockade. Crit. Care Med, 15: 795-796.

Lycklama à Nyeholt, J. and J. Troost (1987) Critical illness polyneuropathy. In: P.J. Vinken, G. W. Bruyn, H. L. Klawans and W. B. Matthews (Eds.), Handbook of Clinical Neurology, Vol. 7 (51), Neuropathies, Elsevier, Amsterdam, pp. 575-585.

Marshall, I. G., S. Agoston, L. H.D.J. Booij, N. N. Durant and F.F. Foldes (1980) Pharmacology of ORG NL 45 compared with other non-depolarizing neuromuscular blocking drugs. Br. J. Anaesthesiol., 52: 115-195.

Oosterhuis, H.J.G. H., J. Newsom-Davis, J.H.J. Wokke, P.C. Molenaar, T. v.Weerden, B. S. Oen, F.G. I. Jennekens, H. Veldman, D. W. Wray, C. Prior and N. M. F. Murray (1987) The slow channel syndrome. Two new cases. Brain, 110: 1061-1079.

Op de Coul, A.A.W., P.C.L.A. Lambregts, J. Koeman, M.J.E. van Puyenbroek, H.J. ter Laak and A. A.W.M. Gabreëls-Festen (1985) Neuromuscular complications in patients given Pavulon ${ }^{8}$ (pancuronium-bromide) during artificial ventilation. Clin. Neurol. Neurosurg., 87: 17-22.

Ouvrier, R. A., J.G. McLeod and T. Conchin (1987) Morphometric studies of sural nerve in childhood. Muscle Nerve, 10: 47-53.

Pestronk, A. and D.B. Drachman (1978) A new stain for quantitative measurement of sprouting at neuromuscular junctions. Muscle Nerve, 1: 70-74.

Roelofs, R. I., F. Cerra, N. Bilka, L. Rosenberg and J. Delaney (1983) Prolonged respiratory insufficiency due to acute motor neuropathy: a new syndrome? Neurology, 33 (Suppl.): 240.

Smit, L. M. E., H. Veldman and F. G. I. Jennekens (1987) Immunohistochemical localization of acetylcholine receptors in human endplates using a monoclonal antibody. J. Histochem. Cytochem., 35: 613-617.

Snavely, R. and G.R. Hodges (1984) The neurotoxicity of antibacterial agents. Ann. Intern. Med., 101: 92-104.

Sokoll, M. D. and S. D. Gergis (1981) Antibiotics and neuromuscular function. Anesthesiology, 55: 148-159.

Standaert, F.G. (1984) Pharmacology of the neuromuscular junction. In: R.A. Brumback and J. Gerst (Eds.), The Neuromuscular Junction, Future Publ., Mount Kisko, pp. 121-202.

Torda, T. (1980) The nature of gentamicin-induced neuromuscular block. Br. J. Anaesthesiol, 52: 325-329.

Tracey, K.J., S.F. Lowry, B. Beutler, A. Cerami, J.D. Albert and G.T. Shires (1986) Cachectin/tumor necrosis factor mediates changes of skeletal muscle plasma membrane potential. J. Exp. Med., 164: 1368-1373.

Wernig, A., M. Pécot-Dechavassine and H. Stöver (1980) Sprouting and regression of the nerve at the frog neuromuscular junction in normal conditions and after prolonged paralysis with curare. $J$. Neurocytol., 9: 277-303.

Williams, A.C., S. Sturman, S. Kelsey, S.F.T. Curran and J. A. Finnegan (1986) The neuropathy of the critical ill. Br. Med. J., 293: 790-791.

Zochodne, D.W., C.F. Bolton and J.J. Gilbert (1985) Polyneuropathy in critical illness: pathological features. Ann. Neurol., 18: 160-161.

Zochodne, D. W., C. F. Bolton, G. A. Wells, J.J. Gilbert, A. F. Hahn, J. D. Brown and W. A. Sibbald (1987) Critical illness polyneuropathy. A complication of sepsis and multiple organ failure. Brain, 110 : 819-842. 